\title{
Working with Research Assistants: Guidelines for Mutually Beneficial Relationships
}

\author{
Rose McCloskey ${ }^{1}$ and Kathryn Weaver ${ }^{2}$ \\ ${ }^{1}$ University of New Brunswick, Saint John, Canada \\ ${ }^{2}$ University of New Brunswick, Fredericton, Canada \\ ${ }^{1}$ rmcclosk@unb.ca, ${ }^{2}$ kweaver@unb.ca
}

\begin{abstract}
Faculty members can face a multitude of demands as they strive to advance through the ranks in academia. The need to demonstrate proficiency in research, teaching, and service can be overwhelming and leave faculty feeling conflicted about where to direct their efforts. By utilizing research assistantships, faculty can receive support to advance their programs of research while simultaneously positioning themselves as effective teachers and agents of the university. In this paper, we discuss the role faculty play in research assistants' development and offer guidelines to facilitate successful research assistantships.
\end{abstract}

Keywords: Academia, faculty, Research assistants, Graduate students

\section{Introduction}

In academia, the path to tenure and promotion is demanding and often defined by teaching success, research productivity, and service commitments. From a professional stance, the Canadian Association of Schools of Nursing [1] also espouses nursing faculty to engage in scholarship through a full range of "intellectual and creative activities that include the generation, validation, synthesis and/or application of knowledge to advance science, teaching, and practice" Emphasis on attaining funding to support research and student development is common [2]. These expectations demand nursing faculty in the professorial rank are funded researchers, successful teachers, and nurse scholars. Striving to meet such broad expectations can be overwhelming and a source of considerable stress for faculty [3][4].

The multitude of expectations placed upon nursing faculty can leave them feeling conflicted about where to direct their energies. Faculty are often forced to balance the competing professional demands and allocate their time to where they are best able to fulfill the multiple roles. For instance, although faculty in the professorial rank often carry heavy teaching loads, they must also build and maintain programs of research. Teaching and research together can be intellectually and physically demanding; and yet, nursing faculty are concurrently expected to provide service to the university, remain abreast of current practice issues, and, in some cases, maintain certification in specialty areas. Faculty can be further conflicted through tenure and promotion appraisals by academic review committees. While the assessment of faculty performance is guided by collective agreements, Roberts and Glod [5] assert that assessment committees may disproportionately scrutinize faculty performance

Article history:

Received (March 16, 2020), Review Result (April 21, 2020), Accepted (May 28, 2020) 
in some areas. As a result, the weight given to any one area of responsibility may vary depending on the composition of the assessment review committee at any particular time. Some argue that faculty productivity be measured quantitatively by publication counts, research funding, and service commitments to the institution and community at large [6][7][8][9]. Others take into account faculty members' impact in their respective fields, such as how the faculty member's research has changed practice or the impact factor of the journals where the faculty member published their work [10]. It is therefore understandable that institutional promotional processes can be a source of considerable frustration and stress. The prospect that the weights given to faculty efforts may vary places pressure on faculty to work strategically to excel in all three areas of teaching, research, and service In this article, we profile the integration of research assistantships within faculty programs of research as a strategy to help faculty demonstrate research proficiency.

\section{Rational for faculty integration of research assistantships}

Hiring students to work as Research Assistants (RAs) allows faculty to fulfill the roles of teacher, researcher, and service provider. In the capacity of researcher, faculty secure funding and produce new knowledge; thus, faculty can incorporate costs associated with RAs into the budgets of research proposals. National funding bodies such as Canada's tri-council agencies support the allocation of research dollars to fund students' work as RAs. One mandate of the Canadian Institutes of Health Research is to build research capacity and to support the training of the next generation of researchers [11]. Hiring students to work as RAs may also provide faculty with otherwise inaccessible funding. To illustrate, many universities allocate funds to the creation of enriched educational environments that help ensure students are provided with supportive learning opportunities. These programs often come in the form of student work grants or studentships to which faculty may apply to hire students as RAs. Albeit small, this funding can be added to the faculty member's teaching and/or funding record while simultaneously providing the faculty member with assistance to their program of research.

Working with student RAs provides opportunities for faculty members to align their research efforts with an institutional emphasis on student-centered education, retention, and promotion [12]. Niemczk [13] further maintains that research activity and building research capacity are critical for universities and hence stresses the importance of involving students in faculty research. Faculty who involve students in research have the potential to attract outstanding students to the university and promote the university by providing innovative experiential learning opportunities, enhancing the student experience, and offering financial support to students employed as RAs.

\section{Review of the evidence}

We searched Academic Search Premier, CINAHL with Full Text, ERIC, APA articles, and SocINDEX with Full-Text databases using the terms: research assistant AND university students AND graduate students NOT (volunteering or volunteer or volunteerism) NOT teaching assistants NOT undergraduate students. Results were limited to publications between 2015 and 2020, English language, and peer-reviewed journal articles. This search strategy as well as using Google Scholar and further manual searching of the bibliographies yielded 45 articles, from which we retained 34 (see Flow chart [Figure 1]) Articles not included focused on managing research labs and transitioning from research assistant to the faculty member. 
Themes from the available literature include characteristics of students as research assistants, perspectives about the journey from student to scholar, and benefits of student research assistantships to students, faculty, and universities. The majority of the articles reported benefits but no pitfalls of enhancing faculty research output through hiring students as RAs. The exception is that Naufel and Beike [14] reported faculty lack preparation or receive minimal training to work with and prepare RAs for risks encountered in the research work. Missing from the body of literature was a description of the faculty's role in hiring and working with students as RAs. Drawing on this literature and our own experiences, we offer guidelines to assist faculty members in identifying and working with student RAs.

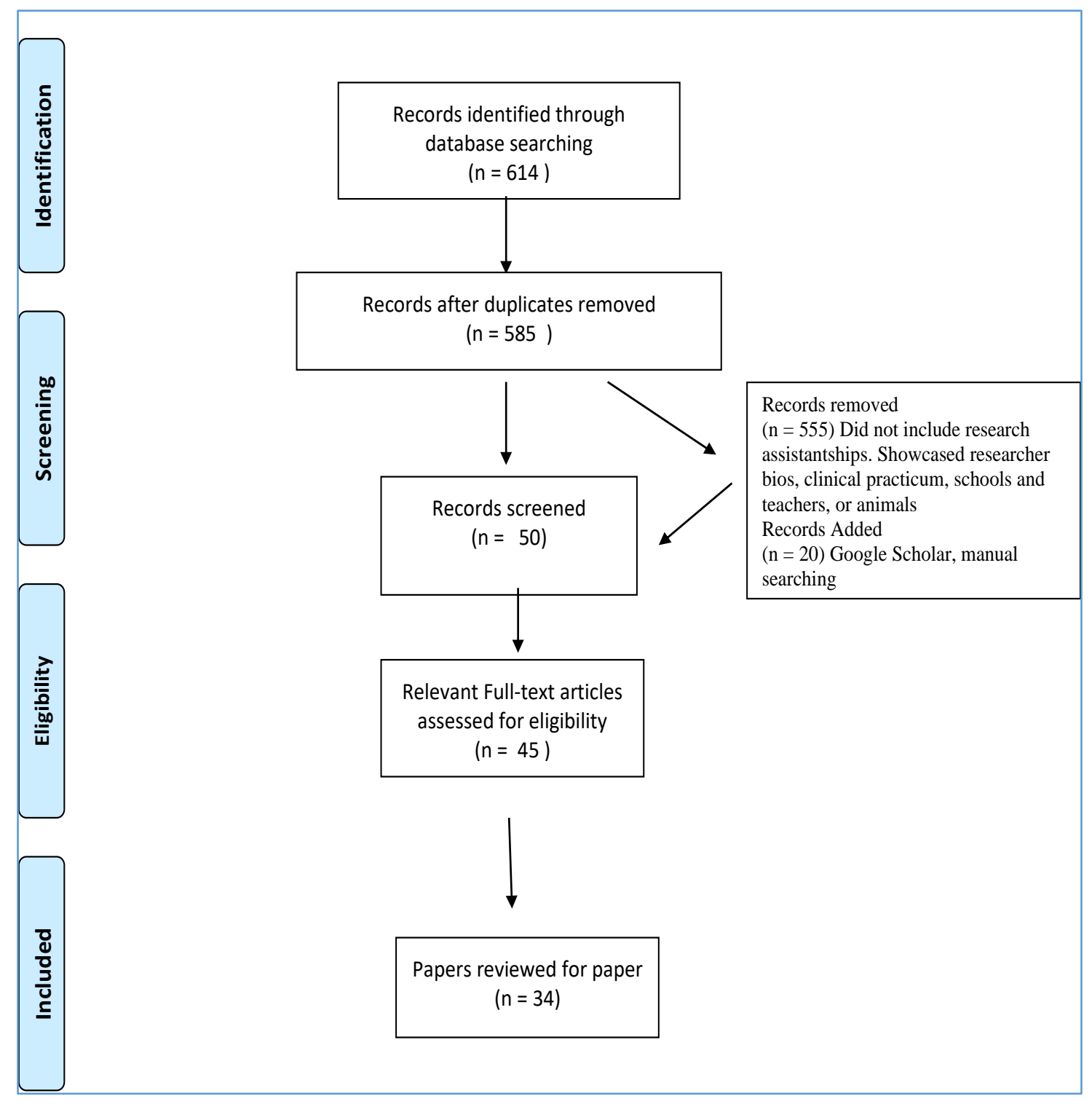

Figure 1. Prisma flow diagram of the search strategy 


\section{1. Characteristics of students as research assistants}

Through their RA experiences, students reported developing a "genuine passion" for the research process because it opened new avenues and perspectives [4]. As RAs, they proved to be individuals who embraced the challenges and the responsibilities placed on them while they strove to meet supervisor expectations [4]. In moving from reading studies into being the person interviewing participants in real-world settings, RAs described satisfaction and enthusiasm. Their budding excitement for research as well as their persistence sustained them through demanding learning challenges and responsibilities such as recruiting and retaining research participants, balancing their academic demands with those of the RA position, and meeting project deadlines. Ultimately, RAs transformed these initial learning struggles into a passion for the research process. Wulf-Andersen and colleagues [15] found students "more ambitious," "more committed," and "more obliged" to "produce good work" when working with faculty (p. 8) RAs, in perceiving their research assistantships as privileged opportunities not offered to peers, expressed intense gratitude toward their RA supervisors for providing rich and diverse RA experiences that jumpstarted the development of their research skills [4].

\subsection{Perspectives about the journey from student to research scholar}

Research assistantships have been viewed as one of the earliest forms of research apprenticeship. When a student enters into a formal research assistantship with a faculty member, the student participates in a process involving training and self-directed learning that will further the research program of the supervising faculty and foster the development of the student's research agenda. Through the RA role, students engage in various research activities (e.g., preparing literature reviews, writing ethics applications, conducting interviews, performing qualitative or quantitative analysis, writing research reports or manuscripts, and presenting findings at conferences) that enable them to participate in the behaviors, skills, and relationships of researchers. These experiences may lead RAs to cultivate an understanding of the interconnectedness of the discrete research steps and develop a broad sense of the entire research process [16]. Thus, a research assistantship facilitates students' scholarly productivity and professional development by progression into research roles that extend their formal education process [4].

The RA process has been described as both "a long journey... continuing throughout [their] life" and also as a staircase because the RA is rising and improving with every step. "When you are climbing up it is difficult. But when you improve yourself the scene will be beautiful"(p. 102) [17]. These participants of a study involving 82 RAs in Turkish educational faculties further described aspects of their journey as a "hopeless period, rocky road, a period of development, ... [feeling like a] deadweight, ... and uncertainty" (pp.102-103) [17]. Although graduate students self-reported not always coming to assistantships with fully developed research skills, they acknowledged their supervisors as placing great trust in the RA's ability to learn the necessary skills. From the perspectives of graduate students, the most valuable research assistantships were those that involved RAs in all stages of the research, from proposal writing to data analysis and reporting [4].

Research assistantships during graduate studies comprise a critical space for RAs to develop interests in research leading to a research identity. However, challenges associated with power imbalances between the RAs and supervisors were difficult to navigate [18]. Mentorship, collaborative research, and keeping a reflective journal were effective strategies to normalize the typical feelings of vulnerability and self-doubt RAs experienced. Recording 
the personal learning journey as a self-study served to support not only self but also others endeavoring to begin research and those who supervise the research projects [18].

\subsection{Benefits of student research assistantships to students, faculty, and universities}

Research assistantships are pathways for RAs to develop as researchers and extend skills to practice [4]. They provide benefits to faculty who serve as supervisors and to institutions. These benefits are varied and encompass academic, personal, and professional components.

\subsubsection{Benefits to students}

Students allowed to engage in one-on-one mentoring research relationships with faculty are generally more satisfied with the educational experience [19][20] and have significantly higher career, core, and statistics/methodology knowledge with advanced self-reported SPSS, critical thinking, and writing skills than non-RA students [21]. Research assistantships provided learning beyond the basic knowledge, comprehension, and application levels of Bloom's Taxonomy to the higher levels of analysis and synthesis [22][23]. Pollon et al. [4] reported developing diverse hard skills during their research assistantships that related to collating and editing a book, completing cost expectancies to bid on projects, writing proposals, refining ethics applications, designing studies, collecting and analyzing data, evaluating programs, analyzing policies, writing reports, and facilitating workshops. They reported learning supplementary soft skills that included being self-directed, collaborating with other people, working as part of a team, negotiating project designs and deliverables, managing expectations, learning best practices for presenting information and communicating findings effectively to stakeholders.

Research assistantships offer an alternative to traditional programmed learning from lectures and textbooks that can be transferable to work settings [4][24]. "You can learn all the research methods and models in school until you are applying them in a practical setting where there are various political agendas and social dynamics at play that's when the real learning happens"(p. 112) [4]. The transferability of research assistantship experiences to practice provides essential learning at a developmentally formative time of consolidating learning and developing research expertise. Having multiple research experiences and responsibilities enables growth and transformation from initial roles as RAs to later roles as competent individuals trusted to independently run entire research programs or be brought in as specialists to guide other research teams [4].

The opportunity to engage in RA-supervisor relationships may be especially appealing to international students [25][26]. International students face many of the same stressors as domestic students; however, these stressors may be amplified by additional cultural, social, linguistic, and financial obstacles [27]. Academically, international students must master new content while also engaging in classroom discussions and active listening in a foreign language [28]. There are opportunities for students to have closer contact with faculty when they work as RAs, providing students with a more comfortable setting to ask questions, seek clarification, and solicit feedback.

\subsubsection{Benefits to faculty}

Student RAs can help faculty fulfill the role of the researcher to develop new knowledge, freeing up faculty time for service and other commitments. RAs can help expedite research efforts by completing tasks that are less complicated yet time-consuming. Examining faculty 
perceptions of RAs, Yalçın, and colleagues [29] compared an RA to a laborer "because s/he has to conduct works that no instructor wants to conduct for a very little amount of money"(p. 26) These work aspects include things such as conducting literature reviews, retrieving necessary resources, distributing questionnaires, or entering data. Middleton and Cons [30] contend that RAs can play an important role in field research as the advanced education and status of an academic may elicit an undesirable barrier between the faculty member and the research participant. This can be especially true when faculty research focuses on vulnerable populations such as students. Although being able to delegate undesirable tasks can be welcoming, research can be a solitary activity; having someone available to discuss ideas and share successes, challenges, and failures can be mutually beneficial [31]. Research assistantships also provide faculty with opportunities to demonstrate their teaching effectiveness through the RAs' improved thinking and analytical skills. Future successes of RAs can be considered a reflection of the faculty member's effectiveness.

\subsubsection{Benefits to universities}

Working with students as RAs provide an opportunity for faculty to respond to university calls for faculty to engage students and to provide experiential learning opportunities. Far too often, students enrolled in classes with large numbers of students do not feel connected to the faculty [32]. Working closely with faculty in research projects helps students feel engaged and more satisfied with their overall university experience.

Universities additionally benefit from cutting-edge research discoveries and enhanced infrastructure which attract new students. Courses taught by research-active faculty incorporate the latest research that may include breaking developments in a discipline. Faculty researchers may also allocate funding toward the design of state-of-the-art research facilities that contain immense libraries and the latest equipment. As a university's reputation grows, major industry players may partner with the university to fund its academic missions.

The benefits of enhanced research output via research assistantships extend beyond the confines of university campuses to benefit local communities, regional and provincial/state economies, the country, the world, and the next generation through research innovation and infrastructure, knowledge development, the economy, and community engagement. Specifically, in educating highly skilled graduates who contribute to their communities, universities play a key role in enhancing lives through research in many fields and industries. In 2012 and 2013, research at US public research universities led to 3,278 patents, produced 522 start-up companies, and yielded 3,094 technology licenses - all of which led to ventures, products, and services that improve society [33]. By 2018, US public universities conducted over $\$ 59.4$ billion of research, driving global progress [34].

\subsubsection{Dark side of students as RAs}

While the many benefits of research assistantships were extolled in the literature reviewed, less often described are any difficulties for RAs as students, faculty who supervise, and their supporting institutions. To begin, RAs can experience unique physical, psychological, and social risks when implementing their assigned responsibilities. Naufel and Beike [14] identify vicarious traumatization as a potential danger to RAs eliciting, transcribing, and analyzing participant accounts of abuse and terror. In addition, RAs may feel coerced to continue to work in unsafe environments out of fear of losing rapport with their research supervisor or letters of recommendation for their future endeavors [14][35]. 
Holding research assistantships has often required RAs to develop research skills or translate nominally existing skills into applied settings at rates that tested their existing capabilities. This pressure was accompanied by an immense sense of responsibility causing RAs to describe their assistantships as very demanding and "not an easy task" (p. 9) [4]. Academic life was a long and toilsome journey for some RAs, one of whom said, "It's like a turtle. Academic life is very slow for me because I always had to do everything myself and others blocked me. My supervisor did not support me" (p. 7) [17]. Research assistantships may be unequally available [36], and because of this, Pollon et al. [4] noted that support to graduate students as RAs would be needed.

To faculty, research assistantships may be reported as time-consuming and contributing little to the research [37]. Worsening this limitation is the fact that most assistant professors have received minimal training on how to effectively make use of research assistantships [38]. In a study from a national sample of assistant professors, Narendorf et al. [38] found low levels of satisfaction regarding the preparation of students for RA work. They identified primary challenges as a lack of student skills and commitment and sufficient time to supervise and train students. In addition, not all faculty had supervisor ability. Negative features were supervisors being unreachable, not democratic, and unsupportive in having high expectations but providing little guidance [38].

The current utilization and the full potential of research assistantships within the academy have not been realized. This is evidenced by a former RA reflecting, "I' $m$ just starting [in the academy] ... Universities have to start rethinking [the RA] role and how they can contribute as a knowledge base to the communities they serve" (p. 13) [4].

\section{Guidelines for strategic research planning}

The review of the evidence indicated multiple advantages to students holding research assistantships. The major drawbacks were limited preparation and institutional support on the part of faculty to adequately train RAs. Faculty are encouraged to continually seek out opportunities to employ students as RAs and carefully plan their role in the inquiry. To facilitate greater research assistantships, faculty members could engage in the following:

- Routinely incorporate expenses related to RAs into the budgets of grant proposals, taking into account institutional policies regarding salary ranges and hiring policies.

- Strategically determine start dates and hours of work that RAs will perform on a project to ensure RAs are introduced to the project at the appropriate time. For example, if the RA is playing a role in recruitment, research ethical approval should be obtained before the RA begins work.

- Ensure faculty availability to orientate the RA to the project and, if hiring multiple RAs,

- have them start together to avoid unnecessary duplication of orientation sessions.

- Consult the university's human resource department to facilitate the RA hiring process and compliance with necessary employment policies and practices related to recruitment, equity and diversity, interview processes, pay structure, and fringe benefits. In the case of international students, the human resource department can provide extra guidance on employment eligibility requirements.

- Develop a job description that reflects position details, duties, performance standards, and

the knowledge and skills required to successfully function in the RA role. We suggest the title of the position accurately reflects its primary duties. For example, if the RA will 
be hired to assist with health-related research, this should be reflected in the job title and may minimize the need to review applications not suitable for the position.

- Seek guidance and mentoring from experienced faculty colleagues or the human resource department for the interview and selection process.

- Clearly outline job expectations, including any potential need for flexibility in hours or location. For instance, our clinically-based research regularly requires us to travel to alternate locations such as private homes and healthcare institutions during untraditional hours such as early mornings, evenings, weekends, and even holidays. Potential RAs need to be aware of these expectations upfront to alleviate unnecessary issues arising after the hiring process is complete.

- Communicate a thoughtful, comprehensive orientation in a manner that is understandable and meaningful to the RA and includes the purpose of the research, its methods, and timelines. Other necessary details are how to contact the faculty member if an issue arises, submit expenses related to the work, and access pay schedules and resources such as the library and photocopying services. Expectations of conduct about research and professional ethics should be discussed in detail and, when applicable, confidentiality agreements signed.

- Set clear expectations for the RA and establish regular follow-up meetings to provide ample opportunity for the RA to ask questions and identify unrealistic work demands. We recommend that work completed to date be reviewed and accompanied by detailed constructive feedback. Waiting until the end of a project to provide feedback may lead to frustration and disappointment on the parts of both the RA and the faculty member.

- Engage the RA in ongoing dialogue about the project to help uncover any

misunderstandings that can be rectified early. Faculty need to be mindful of the demands they place on RAs and be willing to adjust these to accommodate the RAs' academic obligations.

Our guidelines stress carefully assessing student skills from the start of the RA-facultysupervisor relationship and establishing clear expectations. The main task for RAs must be conducting research and projects, attending conferences and seminars, and scholarly writing. The consensus of these responsibilities by faculty and RAs with ongoing feedback from both RAs and their supervisors based on trust and assistance is needed to decrease unclear job definitions for RAs [17]. These revised job definitions must be enforced by institutions and universities.

\section{Conclusion}

As reflected in this paper, the benefits of working with RAs reach far beyond obtaining assistance to complete research goals. RAs can support faculty members in their quest for tenure and promotion by supporting their competency in the areas of teacher, researcher, and service provider to the university. The relationships that develop between RAs and faculty members can be mutually beneficial with students having enhanced learning experiences and faculty members' research endeavors being enriched through the novel perceptions and excitement students bring to the relationship. Despite the benefits of working with RAs, faculty members are advised to enter into these relationships thoughtfully and be willing to provide RAs with comprehensive direction, support, and guidance. Drawing on our own experience with research assistantships, we have put forward guidelines for working with RAs. These include careful planning before hiring RAs, engaging available resources in the 
university to assist with the selection of an appropriate RA, and ongoing management and mentorship of the RA.

\section{References}

[1] Canadian Association of Schools of Nursing, "Position statement: Scholarship among nursing faculty", CASN ACESI, (2013)

[2] L.G. O "Connor and C. Yanni, "Promotion and tenure in nursing education: Lessons learned," Journal of Nursing Education and Practice, vol.3, no.5, pp.78-88, (2013) DOI:10.5430/jnep.v3n5p78

[3] A. Clark and D. Thompson, "Succeeding in research: Insights from management and game theory," Journal of Advanced Nursing, vol.69, no.6, pp.1221-1223, (2013) DOI:10.1111/jan.12061

[4] D.E. Pollon, M. Herbert, S. Chahine, and O. Falenchuk, "From research assistant to professional research assistance: Research consulting as a form of research practice," Journal of Research Practice, vol.9, no.2, Article M6.pp.1-21, (2013)

[5] S.J. Roberts and C. Glod, "Faculty roles: Dilemmas for the future of nursing education," Nursing Forum, vol.48. no.2, pp.99-105, (2013) DOI:10.1111/nuf.12018

[6] F. Brischoux and F. Angelier, “Academia's never-ending selection for productivity," Scientometrics, vol.103, no.1, pp.333-336, (2015) DOI.org/10.1007/s11192-015-1534-5

[7] C. Carpenter, D. Cone, and C. Sarli, "Using publication metrics to highlight academic productivity and research impact," Academic Emergency Medicine, vol.21, no.10, pp.1160-1172, (2014) DOI:10.1111/acem.12482

[8] M. Edwards and S. Roy, "Academic research in the 21st century: Maintaining scientific integrity in a climate of perverse incentives and hyper-competition,” Environmental Engineering Science, vol.34, no.1, pp.51-61, (2017) DOI: 10.1089/ees.2016.0223

[9] A. Ranjan, R. Kumar, A. Sinha, S. Nanda, K. Dave, K., Collette, M., and S.Stawicki, "Competing for impact and prestige: Deciphering the "alphabet soup" of academic publications and faculty productivity metrics," International Journal of Academic Medicine, vol.2, no.2, pp.187, (2016) DOI:10.4103/2455-5568.196875

[10] E. WimmerM. Rethlefsen, C. Jarvis, and J. Shipman, "Understanding research impact: A review of existing and emerging tools for nursing," Journal of Professional Nursing, vol.32, no.6, pp.401-411. J, (2016) DOI: org/10.1016/j.profnurs.2016.05.005

[11] Canadian Institutes of Health Research, our mandate, Retrieved from http://www.cihr-irsc.gc.ca/e/7263.html, (2013)

[12] A. Foote Schwegler, "Aligning institutional processes to support academic rigor: A Quality Matters white paper," (2019)

[13] E. K. Niemczyk, "Preparing researchers of tomorrow,” In M. Kompf \& P. M. Denicolo (Eds.) Critical Issues in Higher Education (pp.51-66) Rotterdam: Sense Publishers, Springer, (2013)

[14] K.Z. Naufel, and D.R. Beike, "The ethical treatment of research assistants: Are we forsaking safety for science?" Journal of Research Practice, vol.9, no.2, Article M11, (2013)

[15] T. Wulf-Andersen, K. Mogensen, and P. Hjort-Madsen, "Researching with Undergraduate students: Exploring the learning potentials of undergraduate students and researchers collaborating in knowledge production," Journal of Research Practice, vol.9, no.2, M9, (2013)

[16] K. Niemczyk, "Expanding the research horizon in higher education: Master's students' perceptions of research assistantships," St. Catharines, ON: Brock University, (2010)

[17] D. Gulmez and H.I. O. Kozan, "A study of research assistants' perceptions about the academic adviser and academic life through metaphors," Journal of Education and Practice, vol.8, no.7, pp.96-106, Retrieved from: https: //files.eric.ed.gov/fulltext/EJ1137345.pdf , (2017) 
[18] M. Kirk and K. Lipscombe, "When a postgraduate student becomes a novice researcher and a supervisor becomes a mentor: A journey of research identity development," Studying Teacher Education, vol.15, no.2, 179-197, (2019) DOI:10.1080/17425964.2019.1587606

[19] C.R. Sears, M.A. Boyce, S.D. Boon, V.M. Goghari, K. Irwin, and M. Boyes, 'Predictors of student satisfaction in a large psychology undergraduate program," Canadian Psychology, vol.58, no.2, pp.148-160, (2017) DOI: 10.1037/cap0000082

[20] C. Woolston, “Graduate survey: A love-hurt relationship,” Nature, vol.550, no.7677, pp.549-552, (2017) DOI: 10.1038/nj7677-549a

[21] L. A. Pawlow and E. J. Meinz, "Characteristics of psychology students who serve as research assistants," College Student Journal, vol.51, no.1, pp.77-80, EJ1132232, (2017)

[22] M. Linn, E. Palmer, A. Baranger, E. Gerard, and E. Stone, "Undergraduate research experiences: Impacts and opportunities,” Science, vol.347, no.6222, pp.627-633, (2015) DOI: 10.1126/science.1261757

[23] D. Lopatto, "Undergraduate research as a high-impact student experience, "Peer Review, vol.12, no.2, pp.27, (2010)

[24] C. Stocks, C. Trevitt, and J. Hughes, "Exploring action learning for academic development in researchintensive settings," Innovations in Education and Teaching International, vol.55, no.2, pp.123-132, (2018) DOI: org/10.1080/14703297.2017.1417886

[25] J. Aponte, B. N. Figueroa, M. Madera, G. Campos-Dominguez, E. Panora, and D. Jaramillo, "Mentoring Hispanic undergraduate and graduate research assistants: Building research capacity in nursing," Journal of Nursing Education, vol.54, no.6, pp.328-334, (2015) DOI:10.3928/01484834-20150515-03

[26] C. Washburn and J. Hargis, "Changes in faculty practice for international students: A case study," Transformative Dialogues: Teaching \& Learning Journal, vol.10, no.1, pp.1-18, (2017)

[27] G. Gorsuch, "International teaching assistants at universities: A research agenda," Language Teaching, vol.49, no.2, pp.75-290, (2016) DOI: 10.1017/S0261444815000452

[28] L. Moores and N. Popadiuk, "Positive aspects of international student transitions: A qualitative inquiry," Journal of College Student Development, vol.52, no.3, pp.291-306, (2011) DOI: 10.1353/csd.2011.0040

[29] M. Yalçın, E. Özoğlu, and A. Dönmez, "Metaphoric perceptions of academic staff about the concept of research assistant," Education \& Science/Egitim ve Bilim, vol.41, no.185, (2016) DOI: 10.15390/EB.2016.4435

[30] T. Middleton and J. Con, “Coming to terms: Reinserting research assistants into ethnography's past and present,” Ethnography, vol.15, no.3, pp.279-290 (2014) DOI: 10.1177/1466138114533466

[31] T. Hutchinson and J. Moran, "The use of research assistants in law faculties: Balancing cost-effectiveness and reciprocity," In Proceedings Faculty of Law Research Interest Group, pp.1-17, Brisbane, (2005)

[32] D. Yelkpieri, M. Namale, K. Esia-Donkoh, and E. Ofosu-Dwamena, "Effects of large class size on effective teaching and learning at the Winneba Campus of the UEW (University of Education, Winneba) Ghana," USChina Education Review, Retrieved from https://files.eric.ed.gov/fulltext/ED532900.pdf, (2012)

[33] American Academy of Arts \& Sciences, "The Lincoln Project: Excellence and access in public higher education,” Retrieved from https://www.amacad.org/LincolnProject, (2016)

[34] National Science Foundation, "Academic research and development: Academic R\&D in the United States," National Center for Science and Engineering Statistics, (2020)

[35] B. Cantwell, J. J. Lee, and Y. Mlambo, "International graduate student labor as mergers and acquisitions," Journal of International Students, vol.8, no.4, pp.1483-1496, DOI: 10.5281/zenodo.1468088, (2018)

[36] E. K. Niemczyk, "Doctoral research education in Canada: Full-time and part-time students' access to research assistantships," Brock Education: A Journal of Educational Research and Practice, vol.26, no.1, pp.52-67, Retrieved from https://files.eric.ed.gov/fulltext/EJ1148310.pdf, (2016)

[37] S. J. Potter, E. Abrams, L. Townson, and J. E. Williams, "Mentoring undergraduate researchers: Faculty mentors' perceptions of the challenges and benefits of the research relationship," Journal of College Teaching \& Learning, vol.6, no.6, pp.17-30, (2009) 
[38] S. C. Narendorf, E. Small, J. A. B. Cardoso, R. W. Wagner, and S. W. Jennings, "Managing and mentoring: Experiences of assistant professors in working with research assistants," Social Work Research, vol.40, no.1, pp.19-30, (2015) DOI: 10.1093/swr/svv037

\section{Authors}

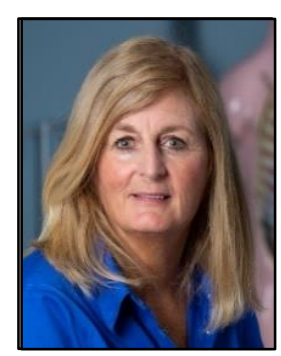

\section{Dr. Rose McCloskey}

Professor, Nursing \& Health Sciences

University of New Brunswick

New Brunswick, Canada

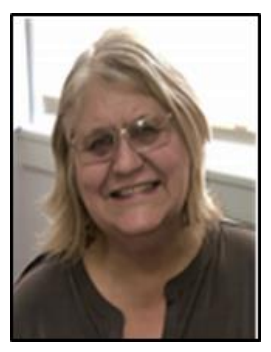

\section{Kathryn Weaver}

Professor, Faculty of Nursing

The University of New Brunswick,

Fredericton, New Brunswick, Canada 
Working with Research Assistants: Guidelines for Mutually Beneficial Relationships

This page is empty by intention. 